\title{
ADDRESSING THE ISSUE OF STIGMA-FREE DESIGN THROUGH CRITICAL DESIGN WORKSHOPS
}

\author{
Anne Britt TORKILDSBY ${ }^{1}$ and Kristof VAES ${ }^{2}$ \\ ${ }^{1}$ The Norwegian Research Laboratory for Universal Design, NTNU Norwegian University of \\ Science and Technology \\ ${ }^{2}$ Department of Product Development, Faculty of Design Sciences, University of Antwerp
}

\begin{abstract}
Stereotypes and prejudices are a ubiquitous cultural phenomenon that can impinge on peoples' wellbeing. Moreover, the power of public stigma can make users of certain products experience discrimination, alienation, and inequality. Such experiences increase the likelihood of individuals rejecting products, services, environments, etc. altogether, often depriving them of e.g. safety, efficiency, and independence. In a worst-case scenario this can lead to a stigmatised condition that triggers further inequality and exclusion.

In an increasingly complex world, it is imperative that those responsible for addressing future needs, challenges, and demands, i.e. the next generation of designers, architects, engineers, etc., are adequately equipped as regards methods and tools for battling existing stereotypes and prejudices related to social growth and development in society. Through this, they will ensure that stigma-free design is a priority when initiating, planning, and executing future projects.

The purpose of this paper is to describe what happens when critical design is used to explore the stigma associated with existing products, services, environments, etc. in the context of interdisciplinary workshops, and to discuss the results so far. Furthermore, the paper examines whether and how this upside-down way of thinking about and performing design is a good contribution to the fields of design, architecture, engineering, etc. as a method of both teaching and learning about equality, diversity, and inclusion.
\end{abstract}

Keywords: Stigma-free design, critical design, product semantics, design for diversity, interdisciplinary workshops

\section{INTRODUCTION}

Imagine that, as a professional designer, architect, or engineer, you are challenged to launch a stigmasensitive pharmacy app, a public toilet, or a white cane onto the market. In such a scenario, the likelihood of being confronted with deeply rooted social and product stereotypes is high. Public perception of stigma-inducing products and associations, along with social stereotypes, can have a large impact on users' social, psychological, and existential wellbeing [1] - no matter which corner of the world they live in. Because they are widely known and shared within cultures, stereotypes may create what Claude Steele calls "a threat in the air" [2] and even challenge the users of products, services, environments, systems, etc. when no-one else is around.

It is safe to say that, in essence, no design methods exist that prevent this phenomenon from occurring due to the fact that people experience and perceive stigma and discrimination subjectively [1]. This dilemma places further pressure on the next generation of designers, etc., who need to meet this challenge in order to someday deliver stigma-free design (SFD).

Thus, this study aims to illustrate how students can approach the topic of "product-related stigma" (PRS) $[3]^{1}$, as Vaes refers to it, through interdisciplinary group work and without specific foreknowledge of the subject matter. PRS was approached in Workshop Series \#4 (WS4) using an especially designed toolkit, which was initially used to develop SFDs [Ibid.]. After this, we introduced critical design (CD),

\footnotetext{
${ }^{1}$ In short, PRS considers stigma-charged interactions and conflicts between products, users, and bystanders within a cultural setting [Ibid.].
} 
which helped the students to let go of traditional problem-solving and tap into the power of problemfinding instead. In short, the result of this study is a novel way of generating SFD that highlights its importance in the minds of students.

\section{THEORY AND CONTEXT}

The experience of stigma is common to all humans [4]: everybody has felt some degree of stigmatisation at some point in their lives, be it a feeling of isolation, alienation, exclusion, or embarrassment, resulting in the feeling of being different from others in some way. Furthermore, 'being different' is commonly related to culture, age, gender, race, health, etc., and can encroach on people's relationships with both objects and other individuals [5]. According to Goffman [6], stigma can be linked to the following characteristics: (1) tribal identities (e.g. race and ethnicity); (2) abominations of the body (e.g. physical abnormalities and blemishes); (3) blemishes of individual character (e.g. mental illness and addiction). However, in the context of WS4, the term 'stigma' refers to social concepts such as stereotypes, prejudice, and discrimination; in other words, people stereotype other people, just as products can stereotype people.

Designing to combat stigma moves beyond function and form, and towards, amongst other things, semantics, embodied messages, profound insight, and empathy. As is discussed above, attaining the skill set required to conduct SFD is a daunting task for young students, particularly in the light of the claim of Oudshoorn, Rommes, and Stienstra that designers often unconsciously use the 'I methodology' ("a design practice in which designers consider themselves to be representative of users" [7][8][9]) when identifying user needs and establishing requirements. This links to Stockton's perspective on negative associations embodied in products; that "designers are unlikely to be able to cater for all of the stigmatising conditions; there will always be some conditions with negative associations" [10]. We as educators thus have an equally daunting task in teaching students how to design for those who are different from themselves - an activity that, according to Woodcock, McDonagh, and Osmond, requires not only personal experience, knowledge, and understanding, but confidence and genuine interest [7][11].

\section{PREVIOUS STUDIES: WORKSHOPS AND TRAINING}

\subsection{Stigma-free design}

Vaes's research on SFD, performed over the course of many years, has shown that PRS mostly occurs during spontaneous and unprepared-for real-life encounters, and furthermore that people who use or wear assistive, protective, or medical devices are often confronted with subtle, clearly visible, or invisible reactions on the part of bystanders or passers-by; instinctive responses, e.g. shock or surprise, various forms of friendliness, or even smiles [3]. According to Vaes, the sum of the aesthetic and functional aspects of the stigma-eliciting product, the product user experiencing the stigma, the observing bystanders, and the cultural context in which the situation is set is what makes an encounter with a person and a product such an impactful experience [Ibid.].

The result of this research is, among other things, the SFD Toolkit that has been applied in (and continuously developed through) design workshops since 2014. Over 220 design students (third-year students from a Bachelor's degree programme in product development) participated in a course titled 'Inclusive Design', which included theoretical background on the topic of PRS and the practical application of the SFD tools. Figure 1 shows some of the results that were generated through the SFD training. 

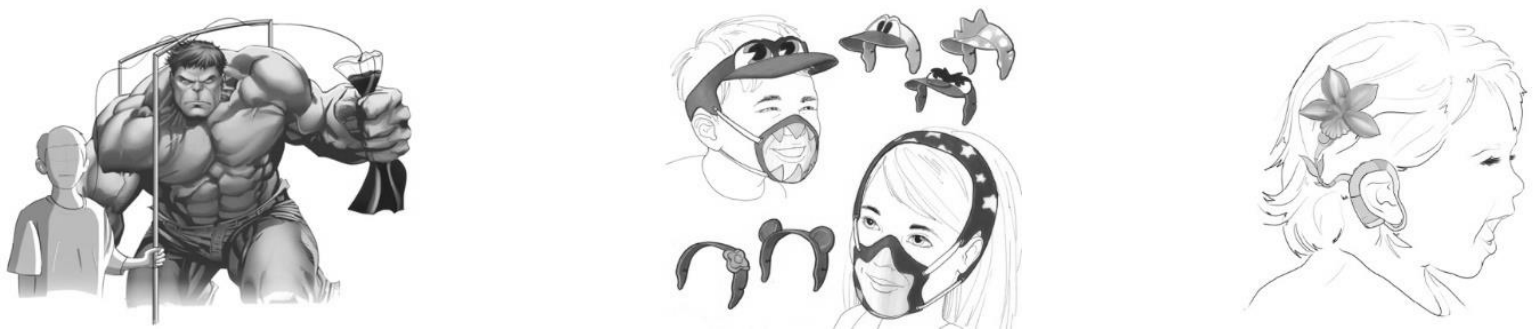

Figure 1. Rough designs sketches generated by design students during SFD training. From left to right: an empowering design concept for an IV fluid stand by

Robin Vandormael and Robrecht Vandekerkhove, a dust mask for children by Sarah Deschryver, and a stigma-reducing alternative for a cochlear implant by Ben Goovaerts and Viktor De Mulder

\subsection{Critical design}

[A] type of design that does not continually strive to make our lives easier, but rather trouble us an annoyance with the aiming to make us look critically at our lives and society in general. [12][13]

Prior to WS4, Torkildsby conducted three series of $\mathrm{CD}^{2}$ workshops to explore different topics, including how institutional environments, such as prisons and hospitals [5], and the built environment in general [7][14] can encroach on individuals' wellbeing in order to test and further develop this way of thinking about design for educational contexts. A total of 14 workshops were executed, and approximately 150 students have been exposed to this kind of design, i.e. "the 'dark side' of design thinking" [5], since 2011. The feedback from the participants is (almost) unanimous: "you learn to look at things from another perspective or attitude", irrespective of educational background and current methods of working, aiding in "realis[ing] the different needs of people in order to help and understand them" [7]. WS4 is, however, the first workshop to target stigma directly, even though this approach was part of the 'critical design examples' (CDEs) ${ }^{3}$ of the previous workshops.
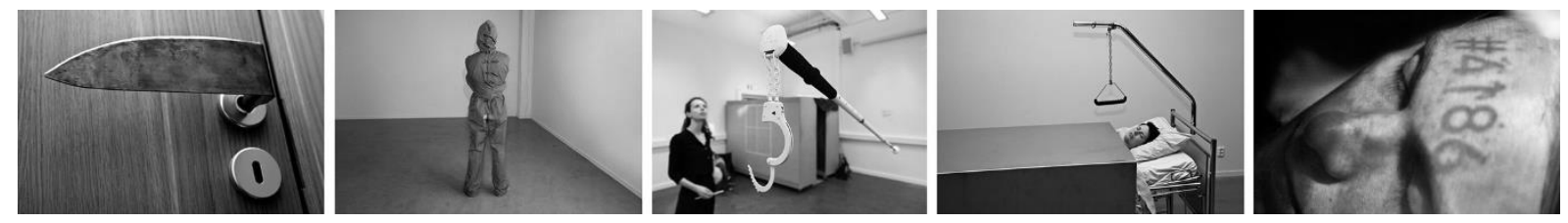

Figure 2. CDEs that were generated during WS1 and WS3. From left to right: a door handle in a remand prison, designed to cut the hand of a prisoner every time they try to open the door [5]; a prison uniform that covers the inmate's body, including the head, while leaving their buttocks exposed [lbid.]; a white cane to be fastened to a visually impaired person using a handcuff [7]; metal bedding for use in an ICU to anchor the patient to the bed [Ibid.]; an identification system to reduce the bedridden patient to a mere number [Ibid.]

\section{WORKSHOP SERIES \#4 - METHODOLOGY AND PARAMETERS}

\subsection{Process: Trends and reflections}

The workshop was designed as a two-stage process; an SFD exploration followed by a CD twist, with the two being accorded equal importance. The participants were 15 second year Master's degree students from the disciplines of architecture, interior architecture, product design, heritage studies, and urbanism and spatial planning, and were divided into five groups by the tutors so as to ensure that all of the teams were interdisciplinary. Both genders were represented, and some of the students had never met before, much less worked in these specific teams before. The workshops proceeded according to the following four steps:

\footnotetext{
${ }^{2}$ According to Dunne and Raby, the pioneers of this approach to design, $\mathrm{CD}$ is an attitude and position; quite simply, it is geared "to make us think" in the way that clever use of satire and irony often do [15]. CD has been used for decades to provoke public debate about the "present social, cultural and ethical implications of design objects and practice" [12].

${ }^{3} \mathrm{~A} C D E$ is the result of employing $\mathrm{CD}$ in a design process [5].
} 
1. Choose a stigma, explore the context, and define six stigma-specific challenges: The PAMS (Product Appraisal Model for Stigma; [3]) questionnaire highlights stigmatic pitfalls and social conflicts between the users of stigma-sensitive products and their surroundings. This checklist of 27 questions helped the students to explore the context of their specific design challenge, identifying the main sensitivities for the product user, bystanders, and society. The questionnaire was presented in the form of a cardboard tetrahedron, which featured nine questions relating to product perception, products in use, etc., on each side, giving a total of 27 questions [3]. After some discussion, the teams chose to work with the following (product-related) stigmas: Team $1-$ laryngectomy; Team 2 - toilet phobia; Team 3 - fear of using public buses; Team 4 - stomas; Team 5 - morning-after pill shaming. At the end of the first day, each team presented a list of the six most challenging and stigmatising aspects related to their design challenge. For Team 1, these were (self-inflicted) illness, a visual handicap, a 'robotic' voice, hygiene, social interactions, and low self-confidence; for Team 2, smell, sound, hygiene, gender, social norms and acceptable behaviours, and privacy; for Team 3, invasion of personal space, exposure to airborne fungi and bacteria, discomfort, a criminal environment, egotism directed towards fellow passengers, and looking poor; for Team 4, people looking, judgement, secrets, leaking in public, confrontations, and mental and physical disability; for Team 5, communicating private medical conditions, loud pharmacists, embarrassing packaging, public places, 'moral police', and exposure.

2. Conceptualise and visualise SFD solutions: In the second phase, the students were provided with PIMS (Product Intervention Model for Stigma; [3]). This consists of 15 cards which visually inspired the students to incorporate user-product attachment, user empowerment, and collective wellbeing into their designs rather than focus solely on the above-mentioned six stigma challenges. Through this, they were challenged to also consider the important factor of user empowerment, or how they might reshape societal and cultural stereotypes. Steps 1 and 2 helped the students to produce a set of ideas, which they presented in plenum before lunch on the third day. This activity also included feedback and assistance from the other students regarding which designs to develop into full concepts.

3. Introduce CD and "the 'dark side' of design thinking" [5], thus turning everything upsidedown: After lunch on the third day, the workshop changed dramatically. Until then, the students had been lured into thinking that they would spend the coming days generating solutions to the chosen PRSs, and so were surprised to find that for the rest of the week they were to generate CDEs illuminating the chosen design challenge rather than solutions to problems. After some time - and for one or two teams, some much-needed supervision - all of the teams slowly but surely began to let go of their problem-solving techniques and design with satire and irony in mind. As only a few of the students had ever heard of $\mathrm{CD}$, and none had practiced it, they took to the task surprisingly well.

4. Generating CDEs and preparing for the exhibition: For the next two days, the students diligently followed a miniature version of the traditional design process (i.e. inspiration, ideation, and implementation), using the above-mentioned six stigma challenges as (functional and social) requirements. They presented their results as milestones during the process and used their peers' critiques to make decisions and so move forward. The teams were free to choose whatever means they wanted to present their concepts, including films, scenarios, models, role-play, etc. However, all of the teams ended up making full-scale models, simply because it was felt that these would "make an impact" or "shock people" (to quote two of the students) during the planned exhibition. On the afternoon of the fifth day, the classroom was emptied then decorated in the manner of a gallery, and at six o'clock the first guests entered to view the five CDEs.

\subsection{Results: Critical design examples}

Considering the short time available to them, the five teams performed brilliantly in developing their CDEs. Written reflections, handed in two weeks after the workshop, confirmed what the tutors had observed throughout the workshop week; that the students found this to be an engaging experience, and that they expressed methodological freedom and playfulness, as was found during WS1 [5], WS2 [14], and WS3 [7]. To quote some of the workshop participants: "For me, switching to critical design was liberating. It was nice to look at the stigma from a different perspective. I got a lot more ideas"; "In architecture, I can use critical design to first point out the problem. In the design process we (almost) always start with research related to the problem or the assignment. We actually dig into the problem. 
After a thorough analysis we look for solutions and start sketching designs. Maybe that's not the right way to start the process?"; "Stigma-free design will always be useful when you are working with any kind of stigma. Critical design will be more used to make a statement and maybe also to open your mind and think differently in the idea-generation phase". As regards the results, CD should speak for itself, as Dunne and Raby [15] argue. Hence, the five CDEs are presented below, without elaborate explanations.
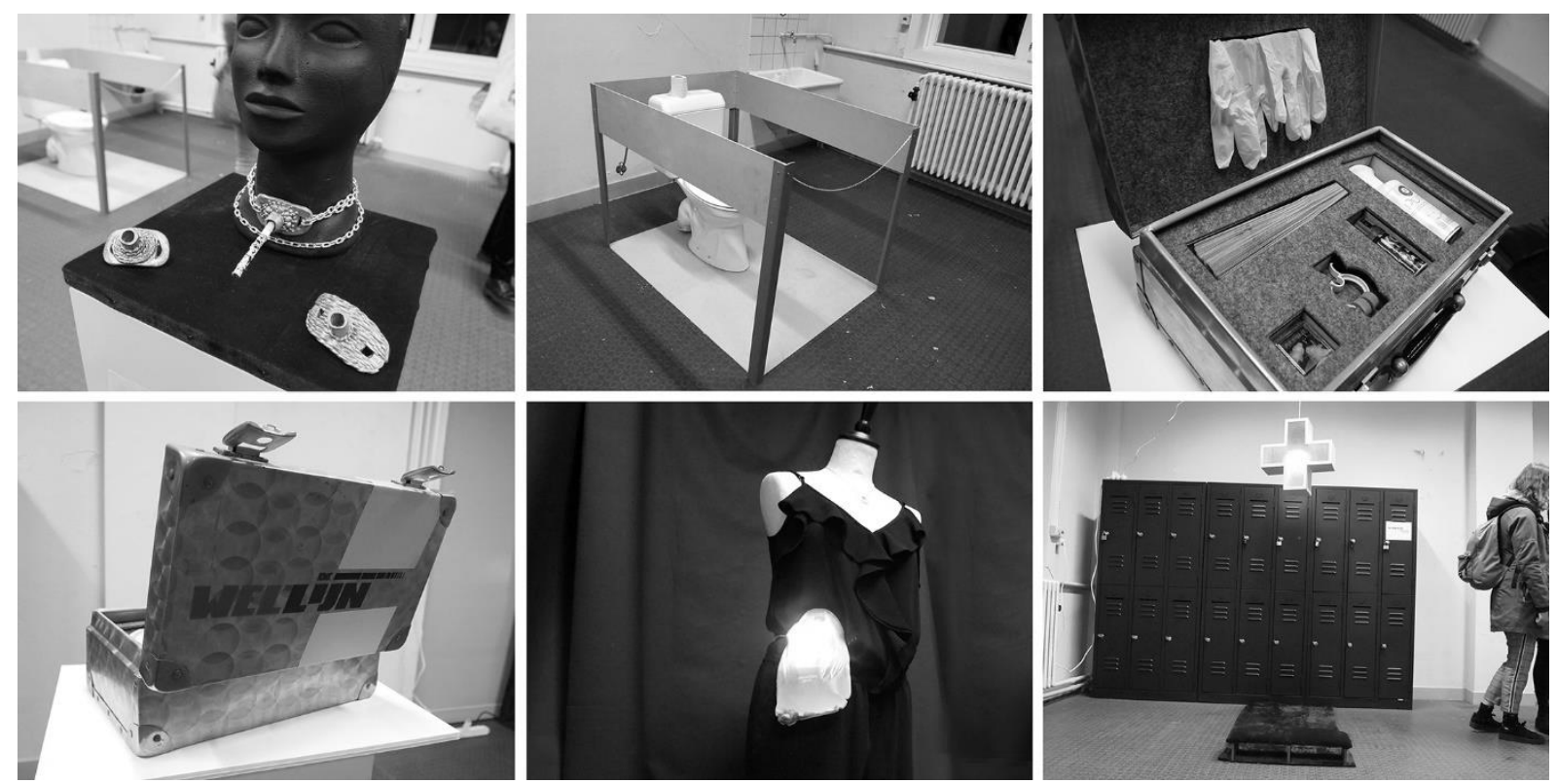

Figure 3. The CDEs generated during WS4. From top-left to bottom-right: CDE \#1, '\#SMOKINGHOT', consisting of larynx protection and gold accessories; CDE \#2, '\#EXPOSED'; a public toilet that leaves nothing to the imagination; CDE \#3, '\#BUSPHOBIA', a survival kit containing basic tools and supplies (earplugs, hand sanitiser, air freshener, etc.) to ensure a more comfortable bus trip (two images); CDE \#4, '\#CARRY-ON', a glittering, shining, bright colostomy bag for use at a disco or when fine dining; CDE \#5, '\#CONFESS', a red velvet kneeling bench and carpet to lead the way to the pharmacy

\section{CONCLUSION AND CONSIDERATIONS}

The primary aim of WS4 was to challenge the next generation of designers, architects, etc. as regards their way of thinking about (product-related) stigmas in order to encourage them to reflect on and stand up, speak out, and act on the themes embodied in the various CDEs'. Due to the students' evolving role in shaping our future, as well as the inevitability of the increasing needs of future generations due to societal challenges such as health, demographic change, and wellbeing [16], it is essential that they are armed with design methods for tackling the challenges of stereotypes, prejudice, and discrimination. Furthermore, they must gain valuable experience of interdisciplinary work in order to be prepared for the 'real' world, outside of university.

Pullin discusses $\mathrm{CD}$ as one of the emerging approaches to overcoming stigma in products in his work on how design can meet the needs of those with disabilities [17]. By combining PRS and CD, the students obtained valuable experience of how the SFD Toolkit (i.e. PAMS and PIMS; [3]) can assist during a design process; moreover, just when they had decided on a concept they were forced to leave their comfort zones, embrace CD, and take a walk on the 'dark side' of design thinking [5]. As expected, the contrast between the traditional way of designing and this approach produced an interesting 'a-ha' moment in the classroom, which then led to interesting discussions - both among the students and with the tutors. To quote two of the students: "By first looking for solutions to the problem, we briefly researched the chosen issue. But by totally changing direction on Wednesday, we were able to make even better and more focused critical designs, I think"; "For me, the switch from stigma-free design to critical design was an eye-opener. Without that switch, we would not have been able to get the point of critical design so fast".

Although more interdisciplinary workshops - at both Bachelor's and Master's degree levels, primarily within creative disciplines such as design and architecture - must be held in order to further develop the 
workshop layout and generate more CDEs, this paper argues that CD is a worthwhile method of teaching and learning about (product-related) stigmas. Incorporating the methodological approaches presented herein into education programmes would provide the next generation of designers, architects, etc. with greater insight into what it means to design for stigma and, moreover, what may occur if they do not consider this aspect of design [Ibid.].

Moreover, the CDEs have another function; they provoke thought experiments among those who come into contact with them, working as 'provo-probes' during the design process and as artefacts in a gallery. Analysis of the reactions of visitors to the WS3 and WS4 exhibitions suggests that the provocative and sensitive elements of the various CDEs have a clear impact on peoples' emotions and could play a key role in raising their awareness. Thus, the CDEs may have a positive impact on social attitudes towards products, services, environments, systems, etc. in the future. Whether CD alone can help in battling stereotypes, prejudices, discrimination, and stigma - in so doing achieving a more diverse and inclusive society - we don't quite know but are sure that it's a good way to start!

\section{REFERENCES}

[1] Major B. and O'Brien L.T. The social psychology of stigma. Annual Review of Psychology, 56, 2005, pp. 393-421.

[2] Steele C.M. A threat in the air: How stereotypes shape intellectual identity and performance. American Psychologist, 1997, 52(6), 613-629.

[3] Vaes K. Product stigmaticity: understanding, measuring and managing product-related stigma, 2014 (Universiteit Antwerpen: Antwerpen).

[4] Crandall, C.S. Ideology and lay theories of stigma: The justification of stigma. In Heatherton T.F., Kleck R.E., Hebl M.R. and Hull J.G. (Eds.), The social psychology of stigma, 2000, p. 126150, (Guilford: New York)

[5] Torkildsby A.B. Existential design - Revisiting the "dark side" of design thinking, 2014. (University of Borås, Swedish School of Textiles: Borås.

[6] Goffman E. Stigma: notes on the management of spoiled identity, 1963 (New Jersey: Englewood Cliffs).

[7] Torkildsby A.B. Empathy Enabled by Critical Design - A New Tool in the Universal Design Toolbox. In Proceedings of Through Design, Diversity and Education Proceedings of Universal Design and Higher Education in Transformation Congress, Dublin, November 2018, pp. 760771 (IOS Press, Dublin).

[8] Oudshoorn N., Rommes E. and Stienstra M. Configuring the User as Everybody: Gender and Design Cultures in Information and Communication Technologies. Science, Technology, \& Human Values, 29, 2004, pp. 30-63.

[9] Akrich M. User representations: Practices, methods and sociology. In Rip A., Misa T.J. and Schot J. (Eds.), Managing technology in society: The approach of constructive technology assessment, 1995, p. 167-184, (Pinter Publishers, London).

[10] Stockton G. Stigma: Addressing Negative Associations in Product Design. In Proceedings of E\&PDE 2009, the 11th Engineering and Product Design Education Conference - Creating a Better World, DS (59), Brighton, September 2009, pp. 546-551 (The Design Society, Glasgow).

[11] Woodcock A., McDonagh D. and Osmond J. Developing empathy for older users in undergraduate design students. Design and Technology Education: An International Journal, 23, 2018, pp. 24-39.

[12] Malpass M. Critical Design in Context - History, Theory and Practises, 2017 (Bloomsbury, London).

[13] Robach C. Critical Design: Forgotten History or Paradigm Shift. In Dencik L., (Ed.), Shift: Design as Usual or a New Rising?, 2005, p. 30-41, (Arvinius, Stockholm).

[14] Torkildsby A.B. Critical Design in Universal Design Settings: Pedagogy turned upside down. Design and Technology Education: An International Journal, 23, 2018, pp. 6-23.

[15] Dunne and Raby. Critical Design FAQ. Available: https://bit.ly/1zsEUP2 [Accessed on 2019, 27 February].

[16] European Commission. Societal Challenges. Available: http://bit.ly/2TslABS [Accessed on 2019, 9 March].

[17] Pullin G. Design Meets Disability, 2009 (Cambridge: MIT Press). 